\title{
Cross-Boundary Teaming for Innovation: Integrating Research on Teams and Knowledge in Organizations
}

\section{Citation}

Edmondson, Amy C., and Jean-François Harvey. "Cross-Boundary Teaming for Innovation: Integrating Research on Teams and Knowledge in Organizations." Harvard Business School Working Paper, No. 17-013, August 2016. (Revised February 2017.)

\section{Permanent link}

http://nrs.harvard.edu/urn-3:HUL.InstRepos:27864357

\section{Terms of Use}

This article was downloaded from Harvard University's DASH repository, and is made available under the terms and conditions applicable to Open Access Policy Articles, as set forth at http:// nrs.harvard.edu/urn-3:HUL.InstRepos:dash.current.terms-of-use\#OAP

\section{Share Your Story}

The Harvard community has made this article openly available. Please share how this access benefits you. Submit a story.

Accessibility 


\section{Cross-Boundary Teaming for}

Innovation: Integrating Research on

Teams and Knowledge in

Organizations

Amy C. Edmondson

Jean-François Harvey

Working Paper 17-013 


\title{
Cross-Boundary Teaming for Innovation: Integrating Research on Teams and Knowledge in Organizations
}

\author{
Amy C. Edmondson \\ Harvard Business School \\ Jean-François Harvey \\ HEC Montréal
}

Working Paper 17-013 


\title{
Cross-Boundary Teaming for Innovation:
}

\section{Integrating Research on Teams and Knowledge in Organizations}

\author{
Abstract \\ Cross-boundary teaming, within and across organizations, is an increasingly popular \\ strategy for innovation. Knowledge diversity is seen to expand the range of views and \\ ideas that teams can draw upon to innovate. Yet, case studies of practice reveal that \\ teaming across knowledge boundaries can be difficult, and innovation is not always \\ realized. Two streams of research are particularly relevant for understanding this \\ challenge: research on team effectiveness and research on knowledge in organizations. \\ They offer complementary insights: the former stream focuses on group dynamics and \\ measures team inputs, processes, emergent states, and outcomes, while the latter closely \\ investigates dialogue and objects in recurrent social practices. Drawing from both \\ streams, this paper seeks to shed light on the complexity of cross-boundary teaming, \\ while highlighting factors that may enhance its effectiveness. We develop an integrative \\ model to provide greater explanatory power than previous approaches to assess cross- \\ boundary teaming efforts and their innovation performance.
}

Keywords: Teams; Knowledge; Innovation 


\section{Introduction}

In a growing number of cases, teams span organizational boundaries, not just functional ones, to pursue innovation. For example, professionals from IT services giant Fujitsu worked with specialists from TechShop, a chain of makerspaces that provide individual customers access to professional equipment, software, and other materials, to develop the first ever mobile makerspace for schools and other community members (Edmondson \& Harvey, 2016a). In the economic development context, specialists in agriculture, economics, finance, marketing, supply chain management and project management from Coca-Cola, the United States Agency for International Development, the Inter-American Development Bank, and the nonprofit organization TechnoServe teamed up on an ambitious project to improve Haitian mango farmers' business practices and incomes (Edmondson \& Harvey, 2016b). Meanwhile, individuals from several multinational corporations, local government agencies, and startups formed a consortium to develop a run-down Paris suburb into an ecologically and technologically "smart" neighborhood (Edmondson et al., 2016). In each of these cases of innovation, individual participants had to work across knowledge boundaries - boundaries associated with differences in expertise and organization in novel settings. They had joined a newly formed temporary group, with fluid membership, which needed to develop rapidly into a high-performing unit to take on an unfamiliar project. This phenomenon is what we call "cross-boundary teaming." It presents a sharp contrast with teams that are well-bounded, reasonably stable, and functionally homogenous such as salespeople on sales teams at an insurance company or researchers on drug development teams at a pharmaceutical firm. 
Research on team diversity in organizational behavior provides useful insights that inform the topic of cross-boundary teaming. Two broad categories of attributes define diversity in this literature. The first is surface-level attributes, or readily detectable differences such as gender, age, and ethnicity. The second, deep-level attributes, includes less visible, underlying differences related to knowledge and work, such as functional or educational background (Harrison et al., 1998). In this paper, we focus on the effects of deep-level attributes on teaming, which we term "knowledge diversity." These differences pertain directly to team knowledge and, through integration, comprise crucial inputs to innovation (Ancona \& Caldwell, 1992a; Pelled et al., 1999). Knowledge diversity expands the range of perspectives that teams can draw upon to innovate.

Yet, when organizations convene groups of individuals with diverse knowledge to develop a new product or service or solve a complex problem, the challenges of teamwork are particularly intense (Edmondson \& Nemhard, 2009). Despite notable successes, qualitative case studies often reveal how difficult teaming across boundaries can be in practice (e.g., Seidel \& O’Mahony, 2014). Tapping the potential performance advantages of integrating diverse knowledge is not simply a matter of getting a diverse group of experts into the same room. Most people take the norms and values within their own professions, organizations, or industries for granted, sharing largely unquestioned assumptions that can thwart communication across boundaries (Cronin \& Wingart, 2007; Edmondson \& Reynolds, 2016). In this paper, we draw from research on team effectiveness and knowledge in organizations to build theory about how strangers with diverse expertise and organizational affiliation can team up in flexible and temporary forms to pursue innovation. 


\section{The need for an integrative model of cross-boundary teaming}

We aim to develop an integrative model of cross-boundary teaming because there are limitations to the applicability of team diversity research for our topic. First, this stream typically examines effects of knowledge diversity in reasonably stable, well-bounded teams seeking to achieve a familiar goal (e.g., Jehn et al., 1999; Shin et al., 2012). Recent emphasis has been put on people working in highly temporary team-like arrangements (e.g., Mortensen, 2014; Valentine \& Edmondson, 2015), but studies of team diversity have not explored the process through which a group of diverse individuals develop into a team ready to solve a new complex problem.

Second, prior research on teams and diversity has emphasized a cognitive view of knowledge, treating it much like information that can be transferred from one individual to another individual or to a group of individuals, largely ignoring knowledge's contextually-embedded nature (Lave \& Wenger, 1991). In contrast, scholars adopting a practice lens stress that not everything we do or understand can be explained by the knowledge we possess (Brown \& Duguid, 2001). From this standpoint, knowing and doing are interconnected through people's work practices (Gherardi, 2000) and localized in particular contexts (Sole \& Edmondson, 2002). As Orlikowski (2002) explains, in high-tech contexts, skillful practice is not based on experts' application of a priori domain knowledge, but instead emerges from practitioners' ongoing and situated actions as they engage with their environment. An implication of this observation is that diverse knowledge is not readily available to all members of cross-boundary teams. To understand the specifics of how groups of diverse individuals can become high- 
performing teams nonetheless, it is crucial to look at what they $d o$, and how they process their diverse knowledge, not only at the expertise they possess.

Consistent with calls for more grounded theories of work in organizations (Barley \& Kunda, 2001), we integrate research streams on team diversity and knowledge boundaries to better inform human resource managers who wish to enable crossboundary teaming within and between organizations. Harrison and Klein (2007) divided diversity into three types: separation (opinions, beliefs, values, attitudes), variety (content expertise, functional background, network ties, industry experience), and disparity (pay, income, prestige, status, authority, power). We build on these categories to suggest that separation, variety, and disparity are often entangled and confounded in practice. Most notably, education or functional backgrounds (variety) produce beliefs or opinions and generate status or prestige. The theoretical benefits of variety of expertise cannot be realized without overcoming the challenge of integrating expertise, and the degree of separation and disparity that may be associated with the expertise variety is likely to determine the degree of challenge. In short, knowledge boundaries can be thick or thinthickened by differences in language, interpretation, or interests (Carlile, 2002, 2004), as well as those of separation and disparity. The construct of knowledge diversity thus can be better understood, and the thickness of boundaries better explained, by drawing on qualitative research on knowledge in organizations.

In the sections that follow, we first review research on team development and team effectiveness, discussing key terms and constructs that have implications for the success of cross-boundary teaming in Section 3. Section 4 looks at prior research on knowledge diversity in teams, and considers the history of mixed results in this work 
along with recent efforts to identify the conditions and processes that increase the chances that knowledge diversity can be put to good use in a team. Section 5 builds on both reviews to develop a new model of cross-boundary teaming, integrating constructs from prior research and drawing on qualitative research on knowledge in organizations. In Section 6 we consider the challenges and opportunities for measuring cross-boundary teaming, drawing from both the teams and knowledge literatures. Finally, Section 7 explores the implications of our model for HR theory and practice, and we conclude (Section 8) with a reminder that cross-boundary teamwork is on the rise and in need of a model that fully appreciates its complexity.

\section{Team development}

Scholars have long been interested in how groups develop over time, and the accumulated research displays agreement on the dynamic, multifaceted nature of team development and team effectiveness. Theoretical models generally describe the maturation of teams through a number of stages that are either sequential (Bennis \& Shepard, 1956; Tuckman, 1965) or non-sequential (Gersick, 1988; McGrath, 1991). Researchers in the sequential tradition describe unitary paths of development that teams follow through the course of their tenure, while researchers who take the non-sequential view focus on describing the factors that trigger shifts in team development. The two streams are not incompatible, however, and have been combined in prior work (e.g., Morgan et al., 1994). Both schools of thought generally acknowledge the complexity and unpredictability of team development: Some teams take one step forward and two steps back; not all teams spend the same amount of time in each stage; and some never reach 
maturity. Many teams have mid-point corrections (Gersick, 1989, 1991), and these experiences can unfold without contradicting other team development models.

Most previous research on team effectiveness has been influenced by the inputprocess-output (IPO) heuristic proposed by McGrath (1964). Recent frameworks build on this heuristic, but have more to say about its inherent dynamics. For instance, Marks et al. (2001) drew attention to the cyclical and episodic nature of the IPO linkages. Notably, the temporally based model they developed highlights the dynamics sustaining team effectiveness, encompassing the interplay between a) emergent affective, cognitive, or motivational states such as team members' attitudes, values, cognitions, and motivation; and b) team processes, which involve team members' interacting with other members and their task environment in the form of cognitive, verbal, and behavioral activities. Other frameworks are similarly explicit about the feedback loop linking team outputs and later inputs (e.g., Ilgen et al., 2005).

Several collective states underpin team effectiveness. For instance, both team mental models (Klimoski \& Mohammed, 1994) and transactive memory (Wegner, 1987) play crucial roles in enabling team performance. Whereas team mental models are shared understandings about task requirements, procedures, and role responsibilities, team transactive memory comprises shared understandings about where particular knowledge is located among team members and how it can help solve specific problems. Psychological safety (Edmondson, 1999), team cohesion (Beal et al., 2003), and team potency (Gully et al., 2002) present further examples of states that emerge through shared experience of teaming. Ultimately, these emergent states are what allow teams to 
develop and pursue specific goals (Hackman, 1990), as well as norms and routines that make them efficient at working towards these goals (Gersick \& Hackman, 1990).

Individual states also emerge during the development of a team. Similar to the multilevel dynamism proposed in models of team development, team socialization has been depicted as a process of mutual influence through which newcomers try to reduce uncertainty by learning about the group's work and context. Generally, when entering new settings, newcomers seek information from interpersonal sources to clarify their role, gain self-efficacy, and develop a sense of belonging (for a review, see Bauer et al., 2007). Other team members support this endeavor by facilitating assimilation to existing norms, routines, and goals. Meanwhile, newcomers try to influence the group, to shape it to their own unique traits and requirements (Anderson \& Thomas, 1996; Moreland \& Levine, 1982). In a survey-based study of 70 project teams in three high-tech organizations, Chen and Klimoski (2003) found that newcomers' performance, as rated by their new team, was principally affected by newcomers' performance expectations for themselves, influenced by both their own self-efficacy and team expectations, and in turn influenced by newcomers' experience. Chen (2005) extended these findings by examining newcomers' adaptation, along with teams' adjustments to newcomers, over time. He found that, while adapting to high-performance teams took longer, newcomers' performance was more likely to keep improving in such contexts, whereas it tended to remain stable in low-performance teams. These findings were consistent with previous theoretical models of mutual influence, as newcomers' performance tends to influence their own subsequent empowerment, as well as the team's subsequent performance. 
In short, individual and collective states emerge through the interpersonal interactions of the newly formed group. These states remain dynamic throughout team development, and may support or impede team performance.

\section{Knowledge diversity and team performance}

Much of the research on team diversity has stressed the benefits of teams that encompass a range of distinct and non-redundant task-relevant resources. The premise has long been that teams can increase their knowledge resources by bringing a diverse group together, because each individual brings a different set of ideas and perspectives that would otherwise have been unavailable to the team (Williams \& O'Reilly, 1998). However, the evidence has been ambiguous. For instance, Bantel and Jackson (1989) showed that higher knowledge diversity leads to higher innovation in a study of top management teams in 199 banks, while Faraj and Sproull (2000) showed that the mere presence of diverse expertise was insufficient for improving team performance in a study of 69 software development teams.

Research on the "common knowledge effect" - or the tendency of teams with diverse information to consider primarily the information shared by everyone (Gigone \& Hastie, 1993) — showed that the simple act of ensuring that uniquely-held information is discussed presents a challenge for teams. Laboratory experiments conducted by Gerald Stasser and his colleagues have consistently shown that team members tend to discuss common (shared) knowledge rather than unique knowledge, even if the unique knowledge is crucial to their team's endeavor (Stasser et al., 1986; Stasser \& Titus, 1985; Stewart \& Stasser, 1995). As a result, the diverse knowledge of cross-boundary team 
members will not be brought to bear on the task to boost team performance, without focused effort to ensure the inclusion of unique knowledge.

Earlier meta-analyses of empirical research found mixed support for advantages of knowledge diversity for team performance (e.g., Bowers et al., 2000; Webber \& Donahue, 2001), and more recent meta-analyses only found performance benefits of a specific type of knowledge diversity (i.e. functional) for a certain types of task (creative/innovative) (e.g., Bell et al., 2011; van Dijk et al., 2012). Shedding additional light on these ambiguous results, Mannix and Neale (2005) concluded that heterogeneity of knowledge attributes is associated with positive outcomes thanks to rigorous debate inside the team, and only when the latter is appropriately aligned with the task. van Knippenberg and Schippers (2007) came to a similar conclusion, emphasizing the mediating role of team information elaboration - the exchange, discussion, and integration of task-relevant information - in converting knowledge diversity into performance benefits. In short, knowledge diversity in itself does not produce performance benefits; in the face of a creative or complex task, knowledge diversity spurs team interaction through which diverse knowledge can be put to good use.

Today, scholars continue exploring the influence of new moderators or mediators on the knowledge diversity-team performance relationship (e.g., Mitchell \& Boyle, 2015; Tekleab et al., 2016). For instance, Homan et al. (2007) coded conversations taking place in experimental groups to show that knowledge diversity was only associated with increased elaboration of information in groups in which members valued diversity, and thus specifically searched for new information and actively listened to others' views. In this stream, knowledge diversity indices are used to capture the distribution of differences 
among members of a team with respect to education, functional knowledge, information or expertise, or industry experience. Operationalized using Blau's index, these knowledge diversity indices are generated from categorical characteristics and corresponds to the proportion of team members in a particular category in relation to the sum of all categories (c.f. Harrison \& Klein, 2007). If a team is homogeneous with regard to the category in question, i.e., if all team members have the same background, the Blau index of the group for knowledge diversity is 0 . If all members of the team have a different background, the Blau index of that team for knowledge diversity approaches 1. Thus, a group of two nurses, two social workers, and one oncologist is seen to be as varied as a group of two nurses, two investment bankers, and one graphic designer. The measure provides no information about the extent of conflicting perspectives these differences may represent. Practitioners would therefore be unable to use this measure to identify appropriate approaches to managing different kinds of cross-boundary dynamics.

Other scholars have introduced the possibility that the positive or negative effects of knowledge diversity may be a function of the way in which it is conceptualized and measured (e.g., Bunderson \& Sutcliffe, 2002; Schoenung \& Dikova, 2016). Recently, van Knippenberg \& Mell (2016) have argued that research on team diversity must cast a wider net in how we understand knowledge diversity, and Waller et al. (2016) have emphasized the need to better account for team members as persons who have prethought ideas and preferences. We aim to provide such insights, and shed additional light on how it can be effectively managed, by complementing team-diversity research with insights from studies of knowledge in organizations.

\section{An integrative model of cross-boundary teaming}


Our framework employs the input-mediator-output-input (IMOI) structure suggested by Ilgen et al. (2005), which depicts teams as complex adaptive systems. Figure 1 shows how drawing on research on knowledge in organizations allows us to go beyond other team-diversity frameworks and provide greater explanatory power for effective crossboundary teaming.

Insert Figure 1 about here

\subsection{Inputs: Knowledge boundary thickness}

Our framework provides a more complex picture of knowledge diversity by accounting for the thickness of the knowledge boundaries to be crossed. Carlile $(2002,2004)$ adopted a relational view of knowledge in organizations and identified three levels of boundaries, formed by the localized, embedded, and invested properties of knowledge. Knowledge is localized as it exists within a given practice in the context of certain problems. Embedded describes the tacit nature of knowledge, which introduces social and material elements that go beyond the cognitive, such that we know more than we can tell. Finally, invested means that developing or redeveloping knowledge is costly for those who have grown their expertise within a given institution. We draw on these insights to suggest that the challenge of cross-boundary teaming depends on the nature of the knowledge. Depending on how localized, embedded, or invested knowledge might be, people face varying challenges related to transferring, translating or transforming it. 
People seeking to integrate knowledge across boundaries face syntactic, semantic, and pragmatic boundaries (Carlile, 2004). Syntactic boundaries are manifested through differences in how language is used. While those involved in such cross-boundary work appreciate their differences, and understand when their performance depends on each other's contribution, language differences may impede the accuracy of communication. If so, knowledge can only be transferred once a common lexicon has been developed to process the information across the boundary. For instance, legal and risk management professionals use different terms, but usually understand how different and dependent they are when working together, and can relatively easily develop a common lexicon to facilitate communication (e.g., Pawlowski \& Robey, 2004).

Semantic boundaries refer to systems of interpretation that produce translation challenges for diverse individuals engaging in novel settings. Novelty creates uncertainty and obscures individuals' assumptions and how they relate to others' assumptions (Skilton \& Dooley, 2010). The more people engage in a particular area of expertise or organization, solving problems, interacting with peers, and producing artifacts, the more robust the system of interpretation they develop (Cronin \& Wingart, 2007; Dougherty, 2001; Wenger, 1998). While one person's interpretation may be rich and specific, each person has only sketchy knowledge of the interpretations of others (Berger \& Luckmann, 1966). As Kenneth Burke (1935) noted, any way of seeing is also a way of not seeing. As a result, people with different interpretations do "not only know different things, but also know things differently" (Dougherty, 1992, drawing upon Ludwik Fleck's work on the sociology of science). Different people thus may look at the same phenomenon and each see different problems, opportunities, and challenges. For example, what designates 
a new product as successful varies according to individuals' respective systems of interpretation. The interpretive systems of business managers might focus on market positioning and competition, while frontline employees may focus on customer benefits (Dougherty, 1992). In the in-depth case study of a multidisciplinary urology cancer team, Oborn and Dawson (2010) showed that different disciplines constructed the patient, as well as their own roles in relation to patients, in diverging ways. The nurse saw the patient as a sufferer in need of counseling; the surgeon saw the patient as a system of organs and bodily tissues to be removed or rearranged; and the oncologist constructed the patient as an evolving malignancy. Such interpretation is so automatic that the people involved may well be unaware of these differences and dependencies. Moreover, semantic boundaries encompass syntactic ones, as any set of knowledge is articulated and enacted within prevailing discourses that define interpretation and systematically disqualify other interpretations from consideration (Carlile, 2004; Parker, 1992). Thus, in addition to common lexicons to span boundaries, semantic boundaries call for common meanings to be developed through shared mutual involvement around problems.

Finally, pragmatic boundaries refer to different and potentially competing interests or agendas across individuals entering situations that offer a great deal of novelty. People follow their own situated rationalities, which implies particular "regimes of worth" (Bolstanski \& Thevenot, 2006) or "principles of evaluation" (Stark, 2009). What counts as "valuable" stems from institutions in which individuals are embedded and for which accumulated knowledge and particular ways of doing things have been established. Professions, for instance, grant access to resources that determine specific groups' access to power, status, and remuneration (Abbott, 1988). Hence, people tend to 
resist innovations that put sympathetic institutions in jeopardy, as Van Maanen and Barley posit: "Innovations which are interpreted as potentially deskilling or which might disrupt the social structure and prestige of the community as it is currently organized will be resisted and, if possible, sabotaged" (1984, p. 90). Solutions that fall outside or go against reigning institutions tend to be ignored or contested by higher-status (ones) professions, while lower-status professions strive to encourage them (Black et al., 2004; Battilana, 2011). Industries, organizations, functions are also institutions within which individuals more or less easily pursue a particular set of interests (Carlile, 2002). Organizations, for instance, have been described as systems of power (Pettigrew, 1973). Drawing upon various case examples, Jarzabkowski and Fenton (2006) showed the potential tension between professional and managerial interests: Professionals will fight for autonomy and expertise, while managers will fight for control and formal authority. At the industry level, NGOs and corporations tend to bind individuals to diverging interests (Battilana \& Dorado, 2010). As with previous boundaries, pragmatic boundaries encompass semantic ones, as interests cause certain perspectives to be systematically preferred or constrained (Oborn \& Dawson, 2010). In such cases, in addition to shared meaning and lexicons, cross-boundary teaming requires the development of shared interests, through negotiation. The integration of diverse knowledge follows an emergent and collaborative process through which the participants ought to engage in transforming their current knowledge into new knowledge that fuels the transformation of others' knowledge (Carlile \& Rebentisch, 2003).

Distinguishing the kinds of knowledge boundaries present in a project is important. We propose that team members' knowledge attributes - the language they 
use, the system of interpretation, and their interests - influence both emergent states and team member interactions. First, individual and collective states are both shaped by team members' knowledge attributes. Our model suggests that people enter new settings with an at least partly tacit view of appropriate role behaviors, required work skills, and others' expectations of them as a new team member. They also arrive with expectations for how the group should work in order to perform well. For example, an ethnographic study of temporary self-organizing project teams in a web-based, interactive marketing company found that professionals with different backgrounds (client services, project management, creative, and technology) entered projects with four distinct understandings of the team's priorities; the enactment of each professional's role thus tended to conflict with the activities of other groups (Kellogg et al., 2006). Depending on the knowledge attributes, emergent states can be more or less rigid, and they can also be more or less conflicting with those of other team members.

Second, the amount and degree of contrast between team members' knowledge attributes affects team member interactions. Research shows that social interaction and communication are negatively related to diverse knowledge attributes. Syntactic boundaries, for instance, impair the accuracy of the communication between team members, which tends to hinder team member interactions such as information sharing, as shown by the survey-based study of multidisciplinary project participants conducted by Kotlarsky et al. (2015). If dealing with robust knowledge boundaries such as pragmatic ones, team interaction may become even more challenging. People tend to perceive members of groups with incongruent interests as less trustworthy (Williams, 2001), and reduced trust inhibits one's willingness to (1) give useful knowledge to 
another person (Andrews \& Delahay, 2000), and (2) listen to and absorb another person's

knowledge—-for instance, by experimenting with something new (Mayer et al., 1995).

\subsection{Mediators: Emergent states and team member interactions}

Emergent states and team member interactions are part of a reciprocal pattern. Our model suggests that team members' boundary-crossing exchanges allow adjustment and reframing of emergent states. As they work across boundaries, team members have the opportunity to examine their own perceptions in a new light and to reflect on the project or on the way they are doing their work. As Marks et al. (2001) have suggested, emergent states are presented as dynamic in nature, and they vary as a function of the interaction in which team members engage. Team members may have only the slightest understanding of either individual or collective states as they enter a new setting, but they may still know enough to spark a conversation with other team members, which they then use to gain additional insights and further expand the emergence of certain states, and so on. Interacting with other team members and reflecting on progress are examples of activities that can help to clarify roles, develop a sense of belonging, and gain selfefficacy. They can also help achieve clarity regarding the team's goals, norms, and routines, hence shaping collective states.

Previous research suggests that team member interactions influence emergent states (for a review, see Mathieu et al., 2008; Waller et al., 2016). Edmondson operationalized team-learning interaction as the following behaviors: "asking questions, seeking feedback, experimenting, reflecting on results, and discussing errors or unexpected outcomes of actions" (1999: 353). Over the years, scholars have zoomed in on specific learning behaviors team members may adopt when interacting together, such 
as talking about problems and mistakes (Carmeli \& Gittell, 2009) or discussing team goals, processes, or outcomes (Schippers et al., 2014). Management scholars who study knowledge boundaries offer similar insights in the sense that they view the process of cross-boundary teaming as based on back-and-forth forms of dialogue in which each participant engages with another's perspective in sufficient depth to facilitate the combination, expansion, and reframing of knowledge (Boland \& Tenkasi, 1995; Tsoukas, 2009). In a study of problem-solving teams, Hargadon and Bechky (2006) found that specialists had to integrate their knowledge with others' knowledge by revealing implicit assumptions about the problem they were trying to solve and by working to understand each other's perspective through probing. In this way, they could uncover each other's mental models, which had implicitly shaped solution paths, and appreciate the constraints or priorities that mattered to the others with respect to each solution.

Drawing on the knowledge-boundaries literature allows us to emphasize an important aspect of team member interactions: its sociomateriality (Leonardi, 2012). Practices involving dialogue (stories and metaphors) but also objects (diagrams, drawings, blueprints in Star \& Griesemer, 1989; prototypes and models in LeonardBarton, 1995) have been described in the literature to help practitioners traverse knowledge boundaries (Okhuysen \& Bechky, 2009).

Learning behaviors, accompanied with objects, are thus useful for teaming across boundaries to broaden understanding of the problem faced, and to find and adapt approaches to solving it. This type of adaptation has been described in several field studies, including a year-long ethnography of technicians, engineers, and assemblers on the production floor of a Silicon Valley semiconductor equipment manufacturing 
company. In this study, Bechky (2003) noticed that inter-group differences were rooted in products' conceptualization and in their production process. Common ground needed to be co-created between members from different groups, so that each could understand how other groups' knowledge fits into their own context, thus developing a collective mental model. To illustrate, Bechky observed an assembler exhibiting a product's physical parts to an engineer to demonstrate a problem. The two experts could then link the physical production process (assemblers' practice) with the conceptual one (engineers' practice), and find a solution that considered, and accommodated, the multiple perspectives involved. In such case, simply trying to transfer knowledge from one group to another, without engaging deeply together, would not have worked.

Yet, objects alone are insufficient for ensuring effective cross-boundary teaming. In an inductive study of six product development teams in three different industries, Siedel and O’Mahony (2014) found that objects left unmanaged actually lead to disunity within teams. To establish a common understanding of desired product attributes, team members first had to scrutinize objects collectively by sharing them widely among themselves, questioning their scope and meaning for the product concept, and second, they had to link objects to design constraints by making connections early in the development process and continuously checking their concept assumptions with emerging design constraints. Third, they had to actively edit objects by identifying a process owner designated to update them and by purging objects that no longer fit the product concept. In short, objects may need to be aligned with learning behaviors to support cross-boundary teaming. 
Our model builds on this work to propose that both individual and collective states, along with team member interactions that includes behaviors and objects, interact

reciprocally, such that each participates in the production or transformation of the others. This dynamic, represented by expanding arrows in Figure 1, may differ in instances where the boundaries spanned are particularly thick (e.g., pragmatic boundaries) compared to when boundaries are relatively thin (e.g., syntactic boundaries) and a limited degree of interaction may be sufficient to bridge gaps. In this way, cross-boundary teaming cannot be understood by analyzing individual components separately. Rather, the activation of emergent states as well as objects and behaviors fuels and helps explain the effectiveness of cross-boundary teaming episodes.

\subsection{Outputs: Individual and team-level benefits}

We propose both individual and team levels outcomes of cross-boundary teaming. The proximal outputs concern team members' learning and professional development, while distal outcomes in our model include process, service, or product innovation. First, people engaged in cross-boundary teaming confront an opportunity for individual benefit (Edmondson \& Nembhard, 2007). We thus build on the assertion that "the [successful] group experience contributes positively to the learning and well-being of individual team members rather than frustrating, alienating, or deskilling them" (Wageman et al., 2005: 4). As team members master new languages, develop different interpretations of a particular situation, or learn how other groups' interests differ from their own, they become broader thinkers who are more capable of transferring, translating, or transforming knowledge across syntactic, semantic, or pragmatic boundaries (Carlile, 
2004). The feedback arrow from outcomes to knowledge attributes in the model represents this proximal outcome.

Second, effective cross-boundary teaming can produce team performance outcomes, such as solving a complex problem or innovating with a successful new product or service. Several studies evidence the relationship between cross-boundary teaming and team performance. For instance, Harvey et al. (2015) examined how a major videogame developer assembled teams of scriptwriters, designers, artists, and programmers to create blockbuster games. The most innovative teams drew upon the "other expertise" of members, who brought additional experience as salsa dancers, graffiti artists, extreme sports aficionados, medieval life enthusiasts, snowboarders and skateboarders, textile artists and yarn bombers. In a study of 224 corporate R\&D teams, Reagans and Zuckerman (2001) similarly found that exchanges between individuals with a wide range of knowledge attributes was key in maximizing teams' performance. Distal outcomes are only achieved once the IMOI loop has been activated throughout crossboundary teaming cycles.

\subsection{Contextual factors: Environment, task, time, and leadership}

The context influences the relationship between inputs and outcomes in cross-boundary teaming, in addition to processes (Ilgen et al., 2005). Context comprises the environment or larger social system in which the team is embedded, the characteristics of the task or work the team is tackling, the timeframe of the teaming effort, and the leadership or governance structure under which the team is acting. For instance, a recent study of cross-functional project teams in two competing automated manufacturing equipment engineering firms with contrasting formal power structures showed that when tasks are 
uncertain and complex, concentrated ownership and governance rights positively influence the performance of diverse teams (Young-Hyman, 2017). Under these conditions, dispersed formal power decreased the productivity benefits of crossfunctional interaction. Performance pressure is another aspect of the environment that can affect diverse teams' performance. In a multimethod field study of 78 audit and consulting teams in two global professional firms, Gardner (2012) found that as performance pressure increased, teams made greater use of general knowledge and less use of domain-specific knowledge because they tended to look for consensus, concentrate on common knowledge, shift focus from learning to project completion, and conform to the status hierarchy.

The team task also influences emergent states and team member interactions. In a survey-based study of 54 work teams from 13 organizations in varied sectors, Schippers et al. (2003) showed that knowledge diversity in newly formed teams encouraged teams' reflexivity when their task outcome was highly interdependent. Yet, other tasks may not necessitate much interaction. If a task can be broken down into simple, relatively independent components (see Baldwin \& Clark, 2000 for a discussion of modularity), team members can work on "their" own components without essential interaction with those working on other components. While potentially efficient, clear task divisions also may cause teams to miss potential benefits of diversity. For instance, while Schmickl and Kieser (2008) showed how successful interdisciplinary product development teams only engaged in limited deep-knowledge sharing-mostly sharing general rather than detailed knowledge to complete their module — the authors also revealed that team member 
interactions in highly innovative projects occurred more often and were more significant than in less innovative ones.

Cross-boundary teaming differs temporally, according to such variables as project lifespan, typical task duration or time needed to achieve a goal (Marks et al., 2001). While some cross-boundary teams may require years to complete an innovation project, others may exist for a couple of hours or even fractions of an hour. In hospital emergency departments, for instance, people work in extremely temporary team-like arrangements. Each patient is treated by a team of professionals, involving various hand offs, and the teams typically convene and disband constantly (Valentine \& Edmondson, 2015). This allows less time for team interaction to discover and leverage each member's expertise. In such settings, teams can successfully accomplish their tasks without deep-knowledge exchange, particularly when there were objects that could support their teaming effort, such as pre-established protocols. For example, Faraj and Xiao (2006) found that in trauma care, teams achieved treatment solutions not through deep-knowledge sharing but through the use of relatively simple protocols that distinguished between anesthesiology, nursing, and surgery disciplines. However, there is also evidence that more open and deeper sharing even in protocol-driven cross-boundary work can produce better performance outcomes (e.g., Edmondson et al., 2001)

Finally, leaders influence team member interactions and emergent states in crossboundary teaming (Edmondson \& Harvey, in press). By reinforcing the kind of behavior they expect from members, providing feedback on whether members have met these expectations, and rewarding those who do, leaders may convey certain messages with regards to emergent states, such as goal priorities (Dragoni \& Kuenzi, 2012). They also 
influence team interaction. For instance, team members tend to notice the behavior of the leader (Tyler \& Lind, 1992), such that his or her responses to team members speaking up either help creating an atmosphere of psychological safety or damage it. Previous research shows that people are more likely to take interpersonal risks within their team if they see the leader as someone who is available and approachable (Edmondson, 1996), who invites input and feedback, and models openness and fallibility (Nembhard \& Edmondson, 2006). In their study of 43 cross-functional new product teams, Lovelace et al. (2001) found that leader effectiveness influenced task disagreement, as well as how free team members felt to express task-related doubts, in addition to directly affecting innovativeness. More recently, in a study of 68 teams in three Chinese companies, Shin et al. (2012) found knowledge diversity to be positively related to individual creativity, but only when leadership was high.

\section{Assessing cross-boundary teaming}

Our cross-boundary teaming model points to the multifaceted nature of knowledge diversity. The three knowledge boundaries range from thin to thick - as we move from syntactic, to semantic, and then pragmatic boundaries. These boundaries rarely become apparent until individuals from different groups engage in cross-boundary work.

Qualitative studies in management show that boundary thickness influences the ease of knowledge integration and call for different strategies to ensure performance. Taking these insights into consideration provides greater explanatory power for assessing crossboundary teaming.

First, most team-diversity studies measure knowledge diversity with an index that assesses proportions of team members from different areas (e.g., Ancona \& Caldwell, 
1992b; Keller, 2001). However, not all diversity is created equal (Harrison \& Klein, 2007). In a meta-analysis, Joshi and Roh (2009) compiled data from nearly 9,000 teams in 39 studies in organizational settings and discovered that the effect sizes associated with different occupation- and industry-level moderators varied significantly across studies. Knowledge diversity effects are not uniform across occupations or industries. Including the nature of the boundaries people must cross to combine their expertise in models of cross-boundary teaming is likely to be crucial to making progress in this important area. For instance, there has to be a difference between Fujitsu engineers teaming up with designers from tech startups and those same engineers teaming up with social workers at an NGO. While the former may face semantic boundaries, the latter may face pragmatic boundaries. This has significant implications. Language differences are on the surface; they are most discernible and thus present the lowest hurdle for cross-boundary teaming. Differences in interpretation and interests run deeper, lead to more diverse or conflicting states, and demand extensive team member interactions (Carlile, 2004; Edmondson \& Smith, 2006).

Our theoretical model invites scholars to use caution when exploring the effects of knowledge diversity from a distance, such as by collecting team composition data without including the specific boundaries to cross. Doing so can undermine the explanatory power of theories drawn from organizational behavior and human resources, as it does not account for the varying effects of knowledge. To better understand how knowledge diversity affects team performance, we need a research focus that considers the localized, embedded, and invested properties of knowledge (Carlile, 2002, 2004). Existing knowledge diversity indices have been the subject of recent criticism (e.g., 
Schoenung \& Dikosa, 2016). One of their drawbacks is the inability to account for differences in types of knowledge boundaries. Observation grids, and eventually new survey measures, could help identify the degree to which cross-boundary teams deal with differences in vocabulary and lexicon, as well as differences in the way team members construe problems and the paths to solve them. The ability to assess the complexity of the boundaries spanned may very well shed new light on the performance of crossboundary teaming efforts. However, continuing with current indices and ignoring the various types of knowledge boundaries and their effects, we risk developing theories that poorly inform the broader challenge of cross-boundary teaming.

Second, drawing upon research on knowledge boundaries allow us to further our understanding of team member interactions that support cross-boundary teaming. Prior research showed that cross-boundary teaming strategies must be adapted to the specific knowledge boundaries to be spanned (Carlile, 2004). Put differently, the more is not always the merrier. For instance, the use of objects during team member interactions should not be taken lightly. In a study of project teams in an architecture firm, Ewenstein and Whyte (2009) found that objects had the unintended negative effect of making differences between groups more salient without providing the desired and necessary common ground to bridge them. Engaging in deep conversations with people from other groups is demanding and comes with the risk of creating interpersonal conflict that can erode team relationships and make future teamwork problematic (Edmondson \& Nehbhard, 2009). Every cross-boundary teaming effort may not require deep issues to be resolved or new agreements to be created. Some may be able to develop integrative 
solutions without deeply sharing each other's knowledge, thus “transcending knowledge differences rather than traversing knowledge boundaries" (Majchrzak et al., 2012).

We need to further our understanding of the contingent benefits of team member interactions during cross-boundary teaming. In the face of specific knowledge boundaries, we need to unveil what learning behaviors should accompany the use of objects, and how much of such team member interactions, are necessary in order to tap into the benefits of knowledge diversity. Current survey scales measure the intensity or frequency at which team members engage in certain learning behaviors. Future research should add more complexity to the analysis of team member interactions by also assessing the use of objects. Given reported differences in knowledge diversity's effects, based on different processes and contexts, it is clear that it matters how knowledge diversity is managed. Considering both learning behaviors and objects should give us a better picture of the processes that are supporting or impeding spanning specific knowledge boundaries.

In the long run, drawing on our model, team scholars may wish to develop longitudinal studies that consider contextual features along with knowledge boundaries at play at different points in time during cross-boundary teaming efforts. The interplay between these emergent states and team member interactions is another vital direction for future research. We argue that emergent states are initially shaped by the knowledge attributes of individuals involved in a cross-boundary teaming effort, but also influence one another. Our model also proposes that emergent states reciprocally influence team member interactions during cross-boundary teaming episodes. This creates a feedback loop that takes initial cross-boundary teaming outcomes, such as evolution in the team 
members' language, interpretation, and interests, back into the teaming cycle until a distal outcome is achieved. Over time, scholars could illuminate the intricacies of crossboundary teaming by identifying which states emerge as particularly problematic when spanning certain knowledge boundaries, and which behaviors and objects are well-suited to steer such teaming efforts in the right direction. Doing so could shed light on how cross-boundary teams evolve when they produce radical innovations. The assumption that thick knowledge boundaries are worth the effort they require from team members, while highly plausible, has yet to be fully examined. Future research investigating success rates of such experiences versus spanning thinner boundaries, as well as examining factors that facilitate thick-boundary crossing, could help managers and policy makers better solve the wicked problems they face today.

\section{Implications of the model for HRM}

Prior work has shown that HRM systems influence an organization's ability to innovate (Schuler \& Jackson, 1987; Shipton et al., 2006) and that team performance is influenced by human resource practices (Richter et al., 2011). Yet, very few scholars have used HR practices in their study of cross-boundary teams (Guillaume et al., 2015). Our integrative model of cross-boundary teaming has implications for HRM practices, in particular with relations to staffing and development, in both domains - innovation and teams.

\subsection{Staffing and socialization}

Our model is particularly relevant for researchers and practitioners concerned with staffing temporary project teams, especially teams working on innovation projects. While managers are often the ones selecting project participants (Solow et al., 2002), we argue that HR professionals have important advisory roles to play in the cross-boundary 
teaming process, as well as in leveraging the right bundles of HR practices. HRM systems should offer a comprehensive view on the competencies available within and across organizations, and should be able to assist in considering the challenges associated with particular combinations of knowledge attributes for those assigned to complex projects. For knowledge domains separated by thick boundaries, additional facilitation such as teamwork training or team-based rewards can be emphasized. Teaming across thick boundaries increases the risk of under-performance. With thoughtful assessments of task characteristics and other contextual features, teams thus can be well composed and better prepared for the challenges that necessarily lie ahead. Thus, HR practitioners can anticipate the need for effective leadership and good process, to leverage knowledge diversity's benefits, when individuals from different fields must work together on an important project for the organization.

Considering the crucial need for interpersonal interactions and learning behaviors when teams must span thick boundaries, HR practitioners have an important role in helping managers who often are in a hurry to get started. For example, they should encourage managers to allow sufficient time for cross-boundary dialogue in psychologically safe environments at the start of a project, along with slack time for thinking, both of which are crucial for innovative endeavors (Mumford, 2000). Furthermore, HRM systems can influence the interactions had by employees involved in cross-boundary teaming. While allowing employees to work remotely is an increasingly popular mechanism for work-life balance (Beauregard \& Henry, 2009; McCarthy et al., 2010), it can be detrimental to building relationships that support cross-boundary teaming efforts. Working from home may increase individual productivity (Standen et al., 1999), 
but reduces opportunities for informal interactions among team members, with adverse effects on emerging states or on performance in cross-boundary teams.

Integration of staff in cross-boundary teams also matters, and HR practitioners should not leave it all in the hands of managers. Newcomers face uncertainty when they enter new settings (Bauer et al., 2007), and a crucial HRM role is to develop and implement practices to facilitate organizational entry. Organizational socialization tactics help newcomers in numerous ways, including performance proficiency, understanding organization politics, language, values, and more (Chao et al., 1994). Socialization practices thus help newcomers deal with uncertainty and fit in to new surroundings (Ashforth et al., 2007; Gruman et al., 2006). Our model suggests attention to helping socialize existing employees moving into new cross-boundary teams, rather than just helping new hires adjust. The process of joining a new interdisciplinary project may require just as much socialization as joining a new company. Such practices may include tours of the location where the project is being developed, meeting other team members, and holding facilitated discussions on the norms, values or rituals for the team. Rituals are something scholars have long recognized as important in building organizational and group identity (Schein, 1985; Van Maanen \& Barley, 1984). Launching new crossboundary teaming efforts with care can help team members gauge each other's differences while developing strong team collective identity (Van der Vegt \& Bunderson, 2005), and may become an increasingly important HRM responsibility.

\subsection{Training and development}

HRM responsibilities include the design and management of training targeted at employees' career development (Tharenou et al., 2007). Exposing employees to training 
and development supports and enhances their career progression within the organization (Ng et al., 2005). Talent management is an increasingly important part of the HR mission (Cappelli \& Keller, 2014), and joining and participating in new cross-boundary endeavors can serve as a springboard to identify and nurture talent within organizations. HRM systems must enable good short-term matches that lead to meaningful careers.

Similar to what has been developed in education with project-based learning (e.g., Blumenfeld et al., 1991), training programs are not limited to a source-recipient model (e.g., Harvey, 2012), and increasingly attempt to motivate learning directly from practice, e.g., work-based learning (Raelin, 1997). Information and communication technology can offer personal learning environments in which learning modules are closely linked to employees' daily activities. Employees thus can share stories with peers engaged in similar activities, seek or give advice, and complete self-reflection exercises. The journey of cross-boundary teaming can serve as an experience for such a program: given the challenge of working in such teams, exposing members to novel and complex task demands and a diversity of functions or professions with their unique priorities and ways of thinking. Models for business and training partnership (e.g., Pak et al., 2016; Price, 2008) could benefit from better integrating cross-boundary teaming challenges. For instance, these solutions could assist project managers in assessing the knowledge boundaries at play, and in developing specific strategies for dealing with particular contingencies.

Working in a cross-boundary teaming context has the potential to help develop participants in several ways. They may increase their knowledge of other fields by working closely with other functions or companies (Edmondson \& Nembhard, 2007). 
They may gain increased experience and an understanding of teams, of solving complex problems, and working with differences in language, interpretation, or interests. Further, cross-boundary teamwork can expand members' networks of collaborators from various areas and improve their boundary-spanning skills. It provides a setting that can foster learning skills for future collaboration or integration in the organization. Organizations that rely heavily on serial, project-style work (e.g., professional services firms, research organizations) likely experience individual development emerging as a direct result of cross-boundary teaming experiences as an important component of the formal training programs offered.

We suggest that projects with highly novel and complex tasks, and those led by more experienced team leaders, present ripe opportunities for team-member professional development. These learning opportunities can be readily identified even before a team is launched. Individual professional development needs thus can be taken into account when staffing such teams, and HRM systems can be designed to identify individuals in need of certain competencies and to match them to particular projects, to support learning and development. In some cases, this may mean convincing managers of the long-term organizational benefits of staffing a project with one member in need of learning, rather than relying only on more experienced people.

Once a team is staffed, group process is likely to make a difference for the learning and development of team members. Team leaders can prioritize team members' individual learning and help facilitate boundary-spanning efforts to coordinate with external groups. Teams that promote a climate of psychological safety will reap not only 
performance and team-learning benefits (Edmondson, 2003), but also more-satisfying developmental experiences for their members.

HR professionals have the opportunity to champion and support training based on cross-boundary teamwork. Team leaders, who are naturally and appropriately concerned with near-term performance outcomes when forming and managing a work group, can also consider cross-boundary teams as a training ground for individual professional development. With this perspective, HR professionals can work with team leaders to consider how cross-boundary projects will develop the capabilities of participants. Individual team members can play a crucial role in building the effectiveness of future such teams. Considering that most cross-boundary teams disband at the end of their project, individuals' professional growth and development may be nearly as important as the actual team distal outcomes, because it builds the future of the organization. Providing worthwhile developmental experiences for team members presents an opportunity for developing the organization's human capital (Lepak \& Snell, 1999). In turn, team members may use and transmit to others these lessons in future projects, such that the organization benefits indirectly from the increased experience and knowledge of members.

One way to help team leaders pay close attention to individual development is to include it in their performance appraisal. This important success factor of crossboundary teaming efforts could be measured by the extent to which individuals consider themselves more capable and better prepared for future cross-boundary team or project work at the conclusion of their project than they were before the cross-boundary team's work began. Individual team members' performance on future cross-boundary teams 
could also represent a useful index to assess team leaders' performance, hence motivating them to care for more than the project's direct outcomes.

The challenges of providing formal off-line education and training to help employees engage in continuous learning are great. Thus, drivers of learning on the job, in action, are particularly important to HRM today. Successfully harnessing these challenging forces can produce superior work outputs and learning for teams and their members (Edmondson \& Nembhard, 2007). Over time, as individuals learn from their own work experiences and use their knowledge to help future teams in the organization, the organization itself improves (Senge, 1990; Edmondson, 2002).

\section{Conclusion}

As the problems organizations face grow in complexity, fluid cross-boundary teaming may be increasingly important for solving them. Teams are vital to the production of innovation (Wuchty et al., 2007), and teams are more likely than individuals to develop innovative solutions (Uzzi et al., 2013). Yet how diverse experts come together, overcome differences in understanding and interests, and create value remains areas in need of both theoretical and practical advances. Pursuing these advances is both daunting and worthwhile.

Van de Ven and Zahra (2016) have emphasized the importance of understanding complexities when crossing knowledge boundaries, while Grant (2016) argued for greater precision in the definitions of knowledge integration constructs and specifications of the relationships between them. Drawing from two streams of research related to knowledge diversity, we sought to better describe the complexity of cross-boundary teaming, while highlighting factors that may be central to its effectiveness. Past research on team 
diversity offered numerous moderators that affect the team diversity-performance relationship in teams, while the research on knowledge and practice explored the situated activities and logics of diverse experts in great depth. Both streams shed light on knowledge diversity, offering complementary insights. Our model of cross-boundary teaming marries these streams to offer HRM researchers and professionals insights and approaches for helping cross-boundary teams tackle complex problems.

\section{References}

Abbott, A. (1988). The system of professions: An essay on the division of expert labor. Chicago: University of Chicago Press.

Ancona, D., \& Caldwell, D. (1992a). Demography and design: Predictors of new product team performance. Organization Science, 3, 321-341.

Ancona, D., \& Caldwell, D. (1992b). Bridging the boundary: External activity and performance in organizational teams. Administrative Science Quarterly, 37, 634665.

Anderson, N., \& Thomas, H. D. C. (1996). Work group socialization. In M. A. West (Ed.), Handbook of Work Group Psychology (pp. 423-450). Chichester, England: Wiley.

Andrews, K. M., \& Delahaye, B. L. (2000). Influences on knowledge processes in organizational learning: The psychosocial filter. Journal of Management Studies, $37,797-810$.

Ashforth, B. E., Sluss, D. M., Harrison, S. H. (2007). Socialization in organizational contexts. International Review of Industrial and Organizational Psychology, 22, $1-70$.

Barley, S. R., Kunda, G. (2001). Bringing work back in. Organization Science, 12, 7695.

Bantel, K. A., \& Jackson, S. E. (1989). Top management and innovations in banking: Does the composition of the top team make a difference?. Strategic Management Journal, 10, 107-124.

Baldwin, C. Y., \& Clark, K. B. (2000). Design Rules: The Power of Modularity. MIT Press.

Battilana, J. (2011). The enabling role of social position in diverging from the institutional status quo: Evidence from the UK National Health Service. Organization Science, 22, 817-834. 
Battilana, J., \& Dorado, S. (2010). Building sustainable hybrid organizations: The case of commercial microfinance organizations. Academy of Management Journal, 53, 1419-1440.

Bauer, T. N., Bodner, T., Erdogan, B., Truxillo, D. M., \& Tucker, J. S. (2007). Newcomer adjustment during organizational socialization: a meta-analytic review of antecedents, outcomes, and methods. Journal of Applied Psychology, 92, 707721.

Beal, D. J., Cohen, R. R., Burke, M. J., \& McLendon, C. L. (2003). Cohesion and performance in groups: a meta-analytic clarification of construct relations. Journal of Applied Psychology, 88, 989-1004.

Beauregard, T. A., \& Henry, L. C. (2009). Making the link between work-life balance practices and organizational performance. Human Resource Management Review, 19, 9-22.

Bechky, B. A. (2003). "Sharing meaning across occupational communities: The transformation of understanding on a production floor". Organization Science, 14, 312-330.

Bell, S. T., Villado, A. J., Lukasik, M. A., Belau, L., \& Briggs, A. L. (2010). Getting specific about demographic diversity variable and team performance relationships: A meta-analysis. Journal of Management, 37, 709-743.

Bennis, W. G., \& Shepard, H. A. (1956). A theory or group development. Human Relations, 92, 415-437.

Berger, P. L., Luckmann, T. (1966.) The Social Construction of Reality. New York, NY: Anchor.

Black, L. J., Carlile, P. R., \& Repenning, N. P. (2004). A dynamic theory of expertise and occupational boundaries in new technology implementation: Building on Barley's study of CT scanning. Administrative Science Quarterly, 49(4): 572-607.

Blumenfeld, P. C., Soloway, E., Marx, R. W., Krajcik, J. S., Guzdial, M., \& Palincsar, A. (1991). Motivating project-based learning: Sustaining the doing, supporting the learning. Educational Psychologist, 26, 369-398.

Boland, R. J., \& Tenkasi, R. V. (1995). Perspective making and perspective taking in communities of knowing. Organization Science, 6, 350-372.

Bowers, C. A., Pharmer, J. A., \& Salas, E. (2000). When member homogeneity is needed in work teams a meta-analysis. Small Group Research, 31, 305-327.

Brown, J. S., \& Duguid, P. (2001). Knowledge and organization: A social-practice perspective. Organization Science, 12, 198-213.

Bunderson, J. S., \& Sutcliffe, K. M. (2002). Comparing alternative conceptualizations of functional diversity in management teams: Process and performance effects. Academy of Management Journal, 45, 875-893.

Burke, K. 1935. Permanence and Change: An Anatomy of Purpose. New Republic: New York, NY. 
Cappelli, P., \& Keller, J. R. (2014). Talent management: Conceptual approaches and practical challenges. Annual Review of Organizational Psychology and Organizational Behavior, 1, 305-331.

Carlile, P. (2002). A pragmatic view of knowledge and boundaries: Boundary objects in new product development. Organization Science, 13, 442-455.

Carlile, P. R. (2004). Transferring, translating, and transforming: An integrative framework for managing knowledge across boundaries. Organization Science, 15, $555-568$.

Carmeli, A., \& Gittell, J. H. (2009). High-quality relationships, psychological safety, and learning from failures in work organizations. Journal of Organizational Behavior, 30, 709-729.

Chao, G. T., O’Leary-Kelly, A. M., Wolf, S., Klein, H. J., \& Gardner, P. D. (1994). Organizational socialization: Its content and consequences. Journal of Applied Psychology, 79, 730-743.

Chen, G., \& Klimoski, R. J. (2003). The impact of expectations on newcomer performance in teams as mediated by work characteristics, social exchanges, and empowerment. Academy of Management Journal, 46, 591-607.

Chen, G. (2005). Newcomer adaptation in teams: Multilevel antecedents and outcomes. Academy of Management Journal, 48, 101-116.

Cronin, M. A., \& Weingart, L. R. (2007). Representational gaps, information processing, and conflict in functionally diverse teams. Academy of Management Review, 32, 761-773.

Dragoni, L., \& Kuenzi, M. (2012). Better understanding work unit goal orientation: Its emergence and impact under different types of work unit structure. Journal of Applied Psychology, 97, 1032.

Dougherty, D. (1992). Interpretive barriers to successful product innovation in large firms. Organization Science, 3, 179-202.

Dougherty, D. (2001). Reimagining the differentiation and integration of work for sustained product innovation. Organization Science, 12, 612-631.

Drach-Zahavy, A., \& Somech, A. (2001). Understanding team innovation: The role of team processes and structures. Group Dynamics: Theory, Research, and Practice, $5,111-123$.

Edmondson, A. C. (1996). Learning from mistakes is easier said than done: Group and organizational influences on the detection and correction of human error. Journal of Applied Behavioral Science, 32, 5-28.

Edmondson, A. (1999). Psychological safety and learning behavior in work teams. Administrative Science Quarterly, 44, 350-383.

Edmondson, A. C. (2002). The local and variegated nature of learning in organizations: A group-level perspective. Organization Science, 13, 128-146. 
Edmondson, A. C. (2003). Speaking up in the operating room: How team leaders promote learning in interdisciplinary action teams. Journal of Management Studies, 40, 1419-1452.

Edmondson, A C. (2012). Teaming: How Organizations Learn, Innovate, and Compete in the Knowledge Economy. San Francisco: Jossey-Bass.

Edmondson, A. C., Bohmer, R. M., and Pisano, G. (2001). Disrupted routines: Team learning and new technology implementation in hospitals. Administrative Science Quarterly, 46, 685-716.

Edmondson, A. C., Harvey, J. F. (2016a). Open Innovation at Fujitsu (A). HBS Case No. 616-034.

Edmondson, A. C., Harvey, J. F. (2016b). Haiti Hope: Innovating the Mango Value Chain. HBS Case No. 616-040.

Edmondson, A. C., \& Harvey, J. F. (in press). Extreme Teaming: Lessons in Complex, Cross-sector Leadership. London, UK: Emerald Group Publishing.

Edmondson, A. C., Moingeon, B., Bai, G., Harvey, J. F. (2016). Building smart neighborhoods at Bouygues. HBS Case No. 617-007.

Edmondson, A. C., \& Nembhard, I. M. (2009). Product development and learning in project teams: the challenges are the benefits. Journal of Product Innovation Management, 26, 123-138.

Edmondson, A. C. \& Reynolds, S. S. (2016). Building the Future: Big Teaming for Audacious Innovation. Oakland, CA: Berrett-Koehler Publishers.

Edmondson, A. C., \& Smith, D. M. (2006). Too hot to handle? How to manage relationship conflict. California Management Review, 49, 6-31.

Ewenstein, B., \& Whyte, J. (2009). Knowledge practices in design: the role of visual representations as epistemic objects. Organization Studies, 30, 7-30.

Faraj, S., \& Sproull, L. (2000). Coordinating expertise in software development teams. Management Science, 46, 1554-1568.

Faraj, S., \& Xiao, Y. (2006). Coordination in fast-response organizations. Management Science, 52, 1155-1169.

Gardner, H. K. (2012). Performance pressure as a double-edged sword enhancing team motivation but undermining the use of team knowledge. Administrative Science Quarterly, 57, 1-46.

Gersick, C. J. (1988). Time and transition in work teams: Toward a new model of group development. Academy of Management Journal, 31, 9-41.

Gersick, C. J. (1989). Marking time: Predictable transitions in task groups. Academy of Management Journal, 32, 274-309.

Gersick, C. J. (1991). Revolutionary change theories: A multilevel exploration of the punctuated equilibrium paradigm. Academy of Management Review, 16, 10-36. 
Gersick, C. J., \& Hackman, J. R. (1990). Habitual routines in task-performing groups. Organizational Behavior and Human Decision Processes, 47, 65-97.

Gherardi, S. (2000). Practice-based theorizing on learning and knowing in organizations: An introduction. Organization, 7, 211-223.

Gigone, D., \& Hastie, R. (1993). The common knowledge effect: Information sharing and group judgment. Journal of Personality and Social Psychology, 65, 959-974.

Grant, R. (2016). Foreword. In Tell, F., Berggren, C., Brusoni, S., and Van de Ven, A. (Eds.) (pp. vii-x). Managing Knowledge Integration Across Boundaries, Oxford, UK: Oxford University Press.

Gruman, J. A., Saks, A. M., Zweig, D. I. (2006). Organizational socialization tactics and newcomer proactive behaviors: An integrative study. Journal of Vocational Behavior, 69, 90-104.

Guillaume, Y. R., Dawson, J. F., Otaye-Ebede, L., Woods, S. A., \& West, M. A. (2015). Harnessing demographic differences in organizations: What moderates the effects of workplace diversity?. Journal of Organizational Behavior, Published online.

Gully, S. M., Incalcaterra, K. A., Joshi, A., \& Beaubien, J. M. (2002). A meta-analysis of team-efficacy, potency, and performance: interdependence and level of analysis as moderators of observed relationships. Journal of Applied Psychology, 87, 819832.

Hackman, J. R. (1990). Groups That Work. San Francisco: Jossey-Bass.

Hargadon, A. B., \& Bechky, B. A. (2006). When collections of creatives become creative collectives: A field study of problem solving at work. Organization Science, 17, 484-500.

Harrison, D. A., \& Klein, K. J. (2007). What's the difference? Diversity constructs as separation, variety, or disparity in organizations. Academy of Management Review, 32, 1199-1228.

Harrison, D. A., Price, K. H., \& Bell, M. P. (1998). Beyond relational demography: Time and the effects of surface-and deep-level diversity on work group cohesion. Academy of Management Journal, 41, 96-107.

Harvey, J. F. (2012). Managing organizational memory with intergenerational knowledge transfer. Journal of Knowledge Management, 16, 400-417.

Harvey, J. F., Cohendet, P., Simon, L., \& Borzillo, S. (2015). Knowing communities in the front end of innovation. Research-Technology Management, 58, 46-54.

Homan, A. C., Van Knippenberg, D., Van Kleef, G. A., \& De Dreu, C. K. (2007). Bridging faultlines by valuing diversity: Diversity beliefs, information elaboration, and performance in diverse work groups. Journal of Applied Psychology, 92, 1189-1199.

Ilgen, D. R., Hollenbeck, J. R., Johnson, M., \& Jundt, D. (2005). Teams in organizations: From input-process-output models to IMOI models. Annual Review of Psychology, 56, 517-543. 
Jarzabkowski, P., \& Fenton, E. (2006). Strategizing and organizing in pluralistic contexts. Long Range Planning, 39, 631-648.

Jehn, K. A., Northcraft, G. B., \& Neale, M. A. (1999). Why differences make a difference: A field study of diversity, conflict and performance in workgroups. Administrative Science Quarterly, 44, 741-763.

Joshi, A., \& Roh, H. (2009). The role of context in work team diversity research: A metaanalytic review. Academy of Management Journal, 52, 599-627.

Keller, R. T. (2001). Cross-functional project groups in research and new product development: Diversity, communications, job stress, and outcomes. Academy of Management Journal, 44, 547-555.

Kellogg, K. C., Orlikowski, W. J., \& Yates, J. (2006). Life in the trading zone: Structuring coordination across boundaries in postbureaucratic organizations. Organization Science, 17, 22-44.

Klimoski, R., \& Mohammed, S. (1994). Team mental model: Construct or metaphor?. Journal of Management, 20, 403-437.

Kotlarsky, J., van den Hooff, B., \& Houtman, L. (2015). Are we on the same page? Knowledge boundaries and transactive memory system development in crossfunctional teams. Communication Research, 42, 319-344.

Lave, J. \& Wenger, E. (1991). Situated Learning: Legitimate Peripheral Participation. Cambridge: Cambridge University Press.

Leonard-Barton, D. (1995). The Wellsprings of Knowledge. Cambridge: Harvard Business School Press.

Leonardi, P. M. (2012). Materiality, sociomateriality, and socio-technical systems: What do these terms mean? How are they related? Do we need them?. In Leonardi, P. M., Nardi, B. A., \& Kallinikos, J. (Eds.) (pp. 25-48), Materiality and Organizing: Social Interaction in a Technological World, Oxford University Press.

Lepak, D. P., \& Snell, S. A. (1999). The human resource architecture: Toward a theory of human capital allocation and development. Academy of Management Review, 24, $31-48$.

Lovelace, K., Shapiro, D. L., \& Weingart, L. R. (2001) Maximizing cross-functional new product teams' innovativeness and constraint adherence: A conflict communications perspective. Academy of Management Journal, 44, 779-793.

Oborn, E., \& Dawson, S. (2010). Knowledge and practice in multidisciplinary teams: Struggle, accommodation and privilege. Human Relations, 63, 1835-1857.

Okhuysen, G. A., \& Bechky, B. A. (2009). Coordination in organizations: An integrative perspective. Academy of Management Annals, 3, 463-502.

Orlikowski, W. J. (2002). Knowing in practice: Enacting a collective capability in distributed organizing. Organization Science, 13, 249-273.

Majchrzak, A., More, P. H., \& Faraj, S. (2012). Transcending knowledge differences in cross-functional teams. Organization Science, 23, 951-970. 
Mannix, E., \& Neale, M. A. (2005). What differences make a difference? The promise and reality of diverse teams in organizations. Psychological Science in the Public Interest, 6, 31-55.

Marks, M. A., Mathieu, J. E., Zaccaro, S. J. (2001). A temporally based framework and taxonomy of team processes. Academy of Management Review, 26, 356-376.

Mathieu, J., Maynard, M. T., Rapp, T., \& Gilson, L. (2008). Team effectiveness 19972007: A review of recent advancements and a glimpse into the future. Journal of Management, 34, 410-476.

Mayer, R. C., Davis, J. H., \& Schoorman, F. D. (1995). An integrative model of organizational trust. Academy of Management Review, 20, 709-734.

McCarthy, A., Darcy, C., \& Grady, G. (2010). Work-life balance policy and practice: Understanding line manager attitudes and behaviors. Human Resource Management Review, 20, 158-167.

McGrath, J. E. (1964). Social Psychology: A Brief Introduction. New York: Holt, Rinehart, and Winston.

McGrath, J. E. (1991). Time, interaction, and performance (TIP): A Theory of Groups. Small Group Research, 22, 147-174.

Mitchell, R., \& Boyle, B. (2015). Professional diversity, identity salience and team innovation: The moderating role of openmindedness norms. Journal of Organizational Behavior, 36, 873-894.

Moreland, R. L., \& Levine, J. M. (1982). Socialization in small groups: Temporal changes in individual-group relations. Advances in Experimental Social Psychology, 15, 137-192.

Morgan, B. B., Salas, E., \& Glickman, A. S. (1994). An analysis of team evolution and maturation. Journal of General Psychology, 120, 277-291.

Mortensen, M. (2014). Constructing the team: The antecedents and effects of membership model divergence. Organization Science, 25, 909-931.

Mumford, M. D. (2000). Managing creative people: Strategies and tactics for innovation. Human Resource Management Review, 10, 313-351.

Nembhard, I. M., \& Edmondson A. C. (2006). Making it safe: The effects of leader inclusiveness and professional status on psychological safety and improvement efforts in health care teams. Journal of Organizational Behavior, 27, 941-966.

Ng, T. W., Eby, L. T., Sorensen, K. L., \& Feldman, D. C. (2005). Predictors of objective and subjective career success: A meta-analysis. Personnel Psychology, 58, 367408.

Pak, A., Carden, L. L., \& Kovach, J. V. (2016). Integration of project management, human resource development, and business teams: a partnership, planning model for organizational training and development initiatives. Human Resource Development International, 19, 245-260 
Parker, I. (1992). Discourse Dynamics: Critical Analysis for Social and Individual Psychology. London, UK: Routledge.

Pawlowski, S. D., \& Robey, D. (2004). Bridging user organizations: Knowledge brokering and the work of information technology professionals. MIS Quarterly, 28, 645-672.

Pelled, L. H., Eisenhardt, K. M., \& Xin, K. R. (1999). Exploring the black box: An analysis of work group diversity, conflict and performance. Administrative Science Quarterly, 44, 1-28.

Pettigrew, A. M. (1973). The Politics of Organizational Decision Making. London, UK: Tavistock.

Price, T. A. (2008). Planning training programmes to support business initiatives: A model for business and training partnership. Human Resource Development International, 11, 427-434.

Raelin, J. A. (1997). A model of work-based learning. Organization Science, 8, 563-578.

Reagans, R., \& Zuckerman, E. W. (2001). Networks, diversity, and productivity: The social capital of corporate R\&D teams. Organization Science, 12, 502-517.

Richter, A. W., Dawson, J. F., \& West, M. A. (2011). The effectiveness of teams in organizations: A meta-analysis. International Journal of Human Resource Management, 22, 2749-2769.

Schein, E. H. (1985). Organizational Culture and Leadership. San Francisco: JosseyBass.

Schippers, M. C., Den Hartog, D. N., Koopman, P. L., \& Wienk, J. A. (2003). Diversity and team outcomes: The moderating effects of outcome interdependence and group longevity and the mediating effect of reflexivity. Journal of Organizational Behavior, 24, 779-802.

Schippers, M. C., Edmondson, A. C., \& West, M. A. (2014). Team reflexivity as an antidote to team information-processing failures. Small Group Research, 45, 731769.

Schmickl, C., \& Kieser, A. (2008). How much do specialists have to learn from each other when they jointly develop radical product innovations?. Research Policy, 37, 473-491.

Schoenung, B., \& Dikova, D. (2016). Reflections on organizational team diversity research: In search of a logical support to an assumption. Equality, Diversity and Inclusion: An International Journal, 35, 221-231.

Schuler, R. S., \& Jackson, S. E. (1987). Linking competitive strategies with human resource management practices. Academy of Management Executive, 1, 207-219.

Seidel, V. P., \& O'Mahony, S. (2014). Managing the repertoire: Stories, metaphors, prototypes, and concept coherence in product innovation. Organization Science, 25, 691-712. 
Senge, P. (1990). The Fifth Discipline: The Art and Science of the Learning Organization. New York, NY: Currency Doubleday.

Shannon, C., \& Weaver, W. (1949). The Mathematical Theory of Communications. Urbana, IL: University of Illinois Press.

Shin, S. J., Kim, T. Y., Lee, J. Y., \& Bian, L. (2012). Cognitive team diversity and individual team member creativity: A cross-level interaction. Academy of Management Journal, 55, 197-212.

Shipton, H., West, M. A., Dawson, J., Birdi, K., \& Patterson, M. (2006). HRM as a predictor of innovation. Human Resource Management Journal, 16, 3-27.

Sole, D., \& Edmondson, A. (2002). Situated knowledge and learning in dispersed teams. British Journal of Management, 13, S17-S34.

Solow, D., Vairaktarakis, G., Piderit, S. K., \& Tsai, M., 2002. Managerial insights into the effects of interactions on replacing members of a team. Management Science, 48, 1060-1073.

Standen, P., Daniels, K., \& Lamond, D. (1999). The home as a workplace: Work-family interaction and psychological well-being in telework. Journal of Occupational Health Psychology, 4, 368-381.

Stasser, G., Taylor, L. A., \& Hanna, C. (1989). Information sampling in structured and unstructured discussions of three-and six-person groups. Journal of Personality and Social Psychology, 57, 67-78.

Stasser, G., \& Titus, W. (1985). Pooling of unshared information in group decision making: Biased information sampling during discussion. Journal of Personality and Social Psychology, 48, 1467-1478.

Star, S. L., Griesemer, J. R. (1989). Institutional ecology, 'translations' and boundary objects: Amateurs and professionals in Berkeley's Museum of Vertebrate Zoology, 1907-39. Social Studies of Science, 19, 387-420.

Stark, D. (2011). The Sense of Dissonance: Accounts of Worth in Economic Life. Princeton: Princeton University Press.

Stewart, D. D., \& Stasser, G. (1995). Expert role assignment and information sampling during collective recall and decision making. Journal of Personality and Social Psychology, 69, 619-628.

Tekleab, A. G., Karaca, A., Quigley, N. R., \& Tsang, E. W. (2016). Re-examining the functional diversity-performance relationship: The roles of behavioral integration, team cohesion, and team learning. Journal of Business Research, 69, 3500-3507.

Tharenou, P., Saks, A. M., \& Moore, C. (2007). A review and critique of research on training and organizational-level outcomes. Human Resource Management Review, 17, 251-273.

Tsoukas, H. (2009). A dialogical approach to the creation of new knowledge in organizations. Organization Science, 20, 941-957. 
Tuckman, B. W. (1965). Developmental sequence in small groups. Psychological Bulletin, 63, 384-399.

Tyler, T. R., \& Lind, E. A. (1992). A relational model of authority in groups. Advances in Experimental Social Psychology, 25, 115-191.

Uzzi, B., Mukherjee, S., Stringer, M., \& Jones, B. (2013). Atypical combinations and scientific impact. Science, 342(6157): 468-472.

Valentine, M. A., \& Edmondson, A. C. (2015). Team scaffolds: How mesolevel structures enable role-based coordination in temporary groups. Organization Science, 26, 405-422.

Van de Ven, A., \& Zahra, S. A. (2016). Boundary spanning, boundary objects, and innovation. Managing Knowledge Integration Across Boundaries. In Tell, F., Berggren, C., Brusoni, S., and Van de Ven, A. (Eds.) (pp. 241-254). Managing Knowledge Integration Across Boundaries, Oxford, UK: Oxford University Press.

van Dijk, H., van Engen, M. L., \& van Knippenberg, D. (2012). Defying conventional wisdom: A meta-analytical examination of the differences between demographic and job-related diversity relationships with performance. Organizational Behavior and Human Decision Processes, 119, 38-53.

van Knippenberg, D., \& Mell, J. N. (2016). Past, present, and potential future of team diversity research: From compositional diversity to emergent diversity. Organizational Behavior and Human Decision Processes, 136, 135-145.

van Knippenberg, D., \& Schippers, M. C. (2007). Work group diversity. Annual Review of Psychology, 58: 515-541.

Van Maanen, J., \& Barley, S. R. (1984). Occupational communities: Culture and control in organizations. In Staw, B. M. and Cummings, L. L. (Eds.) (pp. 287-365). Research in Organizational Behavior, Greenwich: JAI Press.

Wageman, R., Hackman, J. R., Lehman, E. (2005). Team diagnostic survey development of an instrument. Journal of Applied Behavioral Science, 41, 373-398.

Waller, M. J., Okhuysen, G. A., \& Saghafian, M. (2016). Conceptualizing emergent states: A strategy to advance the study of group dynamics. Academy of Management Annals, 10, 561-598.

Webber, S. S., \& Donahue, L. M. (2001). Impact of highly and less job-related diversity on work group cohesion and performance: A meta-analysis. Journal of Management, 27, 141-162.

Wegner, D. M. (1987). Transactive memory: A contemporary analysis of the group mind. In Mullen B., \& Goethals G. R. (Eds.), Theories of Group Behavior (pp. 185208). New York: Springer.

Wenger, E. (1998). Communities of Practice: Learning, Meaning, and Identity. New York: Cambridge University Press.

Williams, M. (2001). In whom we trust: Group membership as an affective context for trust development. Academy of Management Review, 26, 377-396. 
Williams, K. Y., \& O’Reilly, C. A. (1998). Demography and Diversity in Organizations: A review of 40 years of research. Research in Organizational Behavior, 20, $77-$ 140.

Wuchty, S., Jones, B. F., \& Uzzi, B. (2007). The increasing dominance of teams in production of knowledge. Science, 316, 1036-1039.

Young-Hyman, T. (2017). Cooperating without co-laboring: How formal organizational power moderates cross-functional interaction in project teams. Administrative Science Quarterly, 69, 179-214. 
Figure 1. Cross-Boundary Teaming Model

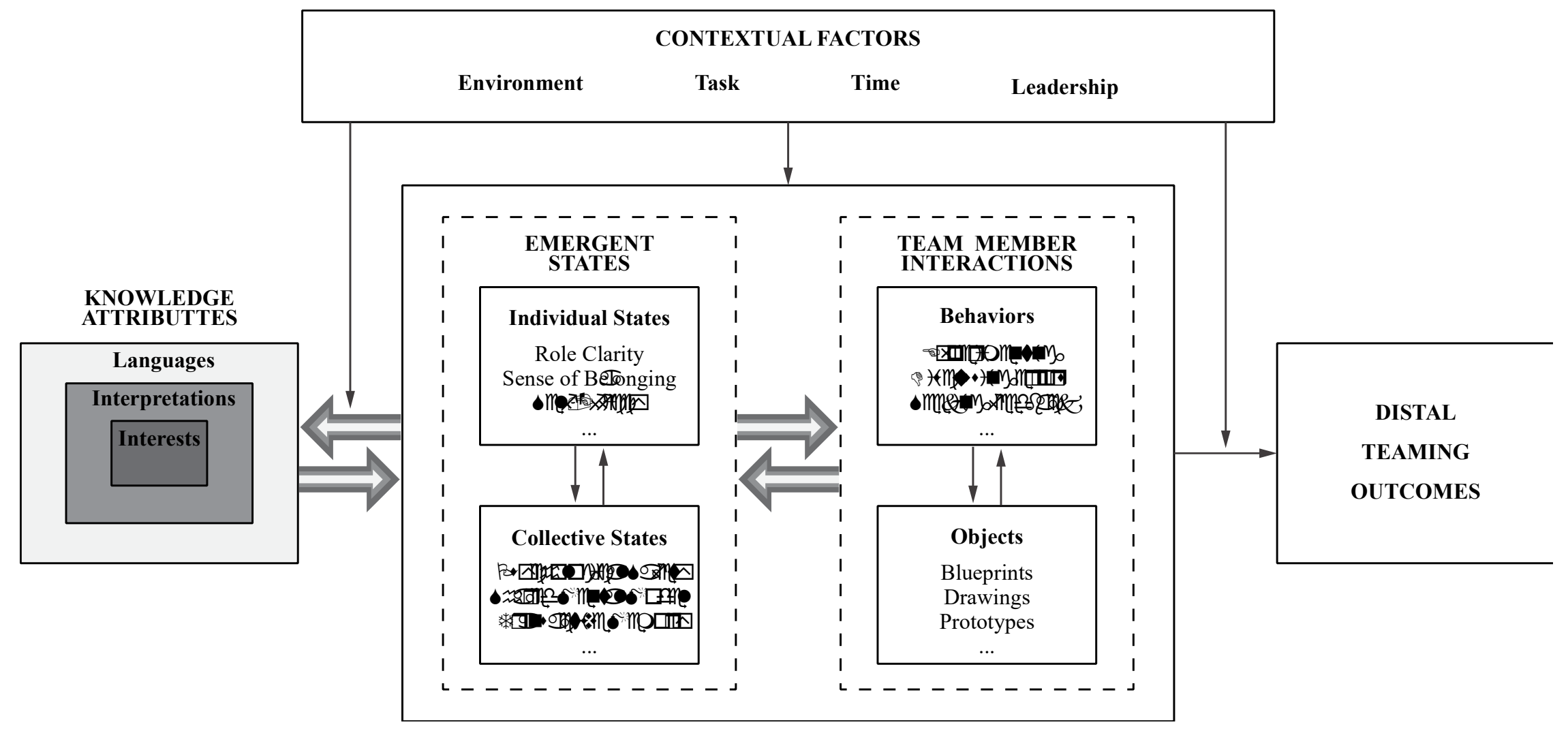

